\title{
SÍNTESIS CURRICULARES
}

\section{ISRAel Chávez BARRETo}

Es tesista de la licenciatura en Lingüística de la Escuela Nacional de Antropología e Historia (ENAH). Actualmente funge como asistente de investigación del doctor Mauricio Beuchot en el Seminario de Hermenéutica del Instituto de Investigaciones Filológicas de la UNAM. Su tesis de licenciatura explora los problemas semiótico-cognitivos de la teoría desarrollada por el semiolingüista argentino Luis J. Prieto. Ha participado como ponente en varios congresos nacionales e internacionales presentando trabajos sobre temas de lingüística y semiótica.

\section{ANDRÉ LAKS}

En 1988 defendió en la Universidad de la Sorbona, París IV, su doctorado de estado (doctorat d'état) titulado: Loi et persuasion. Sur la structure de la pensée politique platonicienne. Ha trabajado como profesor de Filosofía Antigua en diversas universidades: en la Universidad de Lille III (1989-1991 y 1994-2007), en la Universidad de Princeton (1991-1994), en la Universidad de la Sorbona (2007-2012) y en la Universidad Panamericana, en la Ciudad de México, desde 2012. Sus libros principales son: Médiation et coercition. Pour une lecture des 'Lois' de Platon (2005), La filosofía política de Platón a la luz de las Leyes (2007), Histoire, Doxographie, Vérité. Etudes sur Aristote, Théophraste, et la philosophie présocratique (2007), Diogène d'Apollonie (2008) e Introducción a la "filosofía presocrática" (2010). 


\section{Manuel Lavaniegos}

Es licenciado en Filosofía por la Universidad Nacional Autónoma de México y doctor en Arte y Antropología por la Escuela Nacional de Antropología e Historia (ENAH). Sus últimas publicaciones son: "Hermenéutica del mito y hermenéutica analógica" (2015) y "La consagración de la primavera de Ígor Stravinsky: resonancias de una obra maestra" (2015).

\section{Eduardo Mancipe Flechas}

Es filósofo y Magister en Docencia e Investigación Universitaria por la Universidad Sergio Arboleda, en Bogotá, D. C.; realizó estudios doctorales en Ciencias Sociales y Humanas por la Pontificia Universidad Javeriana, Bogotá, Colombia. Actualmente dirige el Centro de Estudios en Desarrollo y Territorio de la Universidad de La Salle. Ha publicado: "Hermenéutica analógica, multidisciplina e interdisciplina" (2014), "La función cultural de los Estudios de InformaciónDocumental" (2014), "El tránsito de la disciplinariedad a la transdisciplinariedad" (2013), Nativos digitales: Transiciones del formato impreso al digital (2013), "Estudios de Información-Documental, Epistemología relacional y Hermenéutica Analógica" (2013) e "Interdisciplinariedad e investigación fenomenológica” (2011), entre otros.

\section{Víctor Hugo Méndez Aguirre}

Es doctor en Filosofía por la Universidad Nacional Autónoma de México (1998). Está adscrito al Centro de Estudios Clásicos del Instituto de Investigaciones Filológicas de la UnAM desde 1998. Autor de El modo de vida idóneo en la República de Platón (2001), ¿Filantropía divina en la ética de Aristóteles? Lectura desde la hermenéutica analógica (2002), Filosofía y política en la República (2006), La persuasión en la utopía platónica (2007) y La diferencia sexual en los diálogos de Platón (2008). Su línea principal de investigación es sobre Platón.

Juan Nadal Palazón

Doctor en Filología por la Universidad de Salamanca (España), maestro en Lingüística Hispánica (UNAM) y licenciado en Ciencias de la 
Comunicación (UNAM). Ganador, entre otros reconocimientos, de las medallas Alfonso Caso y Gabino Barreda (UnAM), del Premio Extraordinario de Doctorado (Universidad de Salamanca) y del Premio Nacional del Consejo Nacional para la Enseñanza y la Investigación de las Ciencias de la Comunicación. Investigador del Seminario de Hermenéutica del Instituto de Investigaciones Filológicas de la UNAM. Tiene como línea de investigación la hermenéutica del discurso periodístico. Autor de los libros El discurso ajeno en los titulares de la prensa mexicana y El sastre aprendiz y sus costuras. Estudio de la narrativa periodística temprana de García Márquez.

\section{Stefano Santasilia}

Es maestro en Filosofía por la Università di Napoli "Federico II" y doctor en Cultura de los Países de Habla Ibérica e Iberoamericana por la Università di Napoli "L'Orientale" con una tesis sobre "La idea del hombre en Eduardo Nicol". Ha realizado estancias de investigación en varias universidades de España y América (UAM y CSIC, Madrid; unam y uAM, México). Ha sido profesor invitado en el Seminario de Hermenéutica del Instituto de Investigaciones Filológicas de la UNAM, colaborando con el doctor Mauricio Beuchot. Sus campos de interés son la antropología filosófica desde el punto de vista fenomenológico, la filosofía de la religión y el pensamiento hispánico. Ha publicado dos monografías, Tra Metafisica e Storia. L'idea dell'uomo in Eduardo Nicol (2010) y Simbolo e corpo. A partire da Eduardo Nicol (2013), además de varios artículos en revistas nacionales e internacionales. Actualmente trabaja como investigador becado en la Università della Calabria, Italia. 